\title{
PERCURSO INVESTIGATIVO PARA CONTEXTUALIZAÇÃO DE METÁFORAS RELATIVAS À GÊNERO E SEXUALIDADE EM LINGUAGENS DOCUMENTAIS
}

\author{
PERCURSO INVESTIGATIVO PARA LA \\ CONTEXTUALIZACIÓN DE METÁFORAS RELATIVAS A \\ GÉNERO Y SEXUALIDAD EN LENGUAJES \\ DOCUMENTALES
}

Fabio Assis Pinho *

\begin{abstract}
RESUMO
Introdução: A construção de uma linha de pesquisa é realizada por um caminho longo e de muitas reflexões teóricas e metodológicas. Nesse sentido, é importante refletir sobre o percurso investigativo que materializou essa linha de pesquisa. Isso porque os estudos que permitem essa rememoração são incipientes. Além disso, esse tipo de reflexão permite que se compreenda a evolução da pesquisa e a compreensão de como os dados foram interpretados e analisados. Objetivo: Neste artigo, objetivou-se apresentar uma reflexão teórica e metodológica a respeito de um percurso investigativo sobre metáforas relativas a gênero e sexualidade em linguagens documentais. Metodologia: A metodologia foi baseada na pesquisa exploratória, documental e bibliográfica, e enfatizou os documentos com temáticas a respeito de questões de gênero e sexualidade no âmbito da organização e representação da informação e do conhecimento. Resultados: Os resultados mostraram o detalhamento da coleta dos dados e a forma como eles foram analisados, sendo as principais interpretações baseadas na coleta de palavras-chave em revistas especializadas, a tradução e categorização dessas palavras, a aplicação do metafiltro, a construção de mapas conceituais e a primeira tentativa de inclusão de metáforas em linguagens documentais. Conclusões: Portanto, essa reflexão sobre o percurso investigativo para contextualização de metáforas promove não apenas uma visão geral, mas possíveis tendências e desafios para futuras pesquisas em organização e representação da informação e do conhecimento e a questão de gênero e sexualidade.
\end{abstract}

Palavras-chave: Organização do conhecimento. Linguagens documentais. Gênero. Sexualidade.

* Doutor em Ciência da Informação pela UNESP - Marília (SP). Coordenador do Programa de Pós-Graduação em Ciência da Informação da UFPE. E-mail: fabiopinho@ufpe.br.

Inf. Inf., Londrina, v. 22, n. 2, p. 117 - 143, maio/ago., 2017.

http:www.uel.br/revistas/informacao/ 
Fabio Assis Pinho

Percurso investigativo para contextualização de metáforas relativas à gênero e sexualidade em linguagens documentais

\section{INTRODUÇÃO}

A Organização e a Representação da Informação e do Conhecimento têm se comportado como uma área de pesquisa com resultados satisfatórios materializados em seus processos, produtos e instrumentos. Nesse sentido, alguns desafios têm sido percebidos quando essa área de pesquisa se utiliza de comunidades discursivas como estudo de caso no intuito de testar suas variáveis.

Desde 2004, a investigação sobre a questão ética na organização e representação da informação e do conhecimento tem se tornado mais substancial. Entretanto, as pesquisas e publicações sobre essa temática são incipientes nos canais de comunicação científica da Ciência da Informação.

Entretanto, foi um artigo de Dahlberg (1992) que chamou a atenção para a necessidade de pesquisas que envolvessem as questões políticas e culturais da organização da informação e do conhecimento. Por conta disso, tornou-se necessário iniciar um percurso investigativo que permitisse compreender os valores éticos inerentes aos processos, produtos e instrumentos da organização e representação da informação e do conhecimento. Ao mesmo tempo em que foi possível a inferência de valores éticos, também foi possível inferir sobre a negação desses valores, ou seja, os problemas éticos.

E por que estudar os aspectos éticos na organização e representação da informação e do conhecimento? Primeiro, pelo fato de que os sistemas de organização e representação da informação e do conhecimento que se pretendem universais têm, na maioria das vezes, refletido desvios e, dessa forma, disseminado uma estrutura de conhecimento que, para um determinado grupo social, não é válido ou aceito, resultando em um constrangimento de uma parcela da sociedade. Segundo, pelo fato de que na literatura da área de Organização e Representação da Informação e do Conhecimento constata-se que, de certa forma, existe um consenso em relação ao fato de que os instrumentos de representação e, inclusive, os atos de classificar e indexar, não são neutros.

Inf. Inf., Londrina, v. 22, n. 2, p. 117 - 143, maio/ago., 2017.

http:www.uel.br/revistas/informacao/ 
Os idealizadores desses instrumentos, bem como os profissionais da informação dedicados a essa tarefa, possuem visões de mundo e crenças definidas. Nesse sentido, pode-se afirmar que os pesquisadores da área admitem a existência de desvios e tendenciosidades nos sistemas de representação da informação e do conhecimento. Nesse sentido, entende-se que o eixo de estudos culturais e políticos no âmbito da organização da informação e do conhecimento abriga os estudos de gênero e sexualidade. E a temática de gênero e sexualidade na organização do conhecimento perpassa pela compreensão do escopo da ética, pois muitos dos termos e conceitos estão carregados de preconceitos e tabus. Esses preconceitos e tabus podem ser disseminados por meio de termos metafóricos ou outras figuras de linguagem. De qualquer maneira, não é comum que termos metafóricos ou figuras de linguagem ingressem como descritores em linguagens documentais justamente pela falta de controle polissêmico. Entretanto, é sabido que muitas comunidades discursivas utilizam (falam e escrevem) termos metafóricos e figuras de linguagem e, por isso, ainda não possuem análises consolidadas para ingressarem em instrumentos que permitam uma recuperação da informação mais precisa.

Nesse sentido, por meio de uma pesquisa exploratória, bibliográfica e documental, onde os corpora de pesquisa foram os documentos publicados com resultados de pesquisa a respeito de questões de gênero e sexualidade no âmbito da organização e representação da informação e do conhecimento, a saber: Pinho (2006), Guimarães e Pinho (2006), Pinho e Guimarães (2006), Guimarães e Pinho (2008), Pinho (2010), Milani e Pinho (2012), Pinho e Milani (2013), Guimarães, Pinho, Cândido e Mota (2014), Pinho (2014), MartínezÁvila, Guimarães, Pinho e Fox (2015) e Guimarães, Pinho e Milani (2016). Nesse sentido, a análise retrospectiva desses trabalhos publicados permite que se vislumbre a materialização de uma linha de pesquisa a partir de seus obstáculos e desafios.

Inf. Inf., Londrina, v. 22, n. 2, p. 117 - 143, maio/ago., 2017. 
Fabio Assis Pinho

Percurso investigativo para contextualização de metáforas relativas à gênero e sexualidade em linguagens documentais

Por isso, este trabalho teve como objetivo geral apresentar uma reflexão teórica e metodológica a respeito de um percurso investigativo sobre metáforas relativas a gênero e sexualidade em linguagens documentais.

\section{TRAJETÓRIA DO PERCURSO INVESTIGATIVO}

Em 2004, Pinho (2006) iniciou um percurso investigativo com algumas considerações, tais como: a) conversão dos atuais sistemas de representação em sistemas eticamente aceitáveis; b) que as crenças dos usuários devem estar refletidas no sistema de representação; c) competências profissionais respaldadas na ética (reflexão crítica, atuação ética, compreensão discursiva e de diferentes línguas, com intuito de identificar problemas éticos); d) identificação de valores inerentes às atividades de organização e representação da informação e do conhecimento (transculturalidade na mediação, multilinguismo e garantia e hospitalidade cultural). Esses valores orientam a conduta profissional com desejo de atuação ética, baseados principalmente em um valor de caráter geral: respeito.

Além disso, os valores de transculturalidade na mediação, multilinguismo e garantia e hospitalidade cultural refletem aspectos dos princípios de uso de Cutter; e) a necessidade de diálogo, não com propósito de confronto, mas imbuído de uma necessidade de compreender o outro, o diferente; f) propostas de soluções para os problemas éticos identificados em sistemas de representação da informação e do conhecimento sejam por meio de diretrizes baseadas em premissas universais, sejam por meio de uma mudança paradigmática na área, em que a transculturalidade deva ser considerada como visão dialógica, seja ainda por meio do tratamento igualitário de línguas nos instrumentos de representação, cuja base se dá por normas que alertam para as dimensões políticas e culturais da língua.

A partir desse entendimento e da interpretação dos valores e problemas éticos, em 2007, Pinho (2010) buscou para compreender como as linguagens documentais brasileiras incorporavam termos oriundos da temática da homossexualidade masculina. Dessa forma, foram coletadas palavras-chave

Inf. Inf., Londrina, v. 22, n. 2, p. 117 - 143, maio/ago., 2017. http:www.uel.br/revistas/informacao/ 
Fabio Assis Pinho

Percurso investigativo para contextualização de metáforas relativas à gênero e sexualidade em linguagens documentais

atribuídas aos artigos publicados em revistas científicas internacionais especializadas na temática da homossexualidade e que foram cotejadas, enquanto assuntos, com a possibilidade de enquadramento em três linguagens documentais brasileiras.

A coleção das palavras-chave foi composta por aquelas atribuídas aos artigos científicos publicados no Journal of Homosexuality, Sexualities e Journal of Gay \& Lesbian Mental Health, entre os anos de 2007 a 2010. As revistas foram selecionadas por representarem três grandes áreas do conhecimento que estudam a temática, ou seja, a própria área da homossexualidade, a psicologia e a medicina, respectivamente. Assim, o autor analisou o acervo de palavras dessa comunidade em torno de suas temáticas por meio da organização do conhecimento. A escolha por revistas internacionais foi feita mediante ao seu direcionamento, especificidade e foco na temática. Abrangência que não foi encontrada nas revistas nacionais sendo estas mais genéricas, dificultando assim a seleção (PINHO, 2010).

$O$ resultado sugeriu que as linguagens documentais analisadas ainda não possuíam uma adequação e nem tampouco uma especificidade suficiente para a representação da temática em questão e isso não é somente pela baixa proporção com a qual conseguem "traduzir" ou normalizar os termos, mas também por alguns fatores como, por exemplo, a tradução das palavras, a estrutura da linguagem documental e a presença de figuras de linguagem. Por conta disso, foi destacado que o assunto "homossexualidade" estava dividido entre dois aspectos nas linguagens documentais: a) integrar-se com o todo universal ou b) separar-se em uma minoria visível. Esses dois aspectos podem ser resumidos a uma questão de se ter uma representação com ou sem destaque. A visão minoritária pede uma representação com destaque, onde a terminologia e a estrutura da linguagem chamem a atenção para a diferença, fazendo com que a parte se distinga do todo. A visão universalizante, por sua vez, pede uma representação sem destaque, onde a terminologia e a estrutura da linguagem não chamem a atenção para as diferenças, enfatizando o todo unificado.

Inf. Inf., Londrina, v. 22, n. 2, p. 117 - 143, maio/ago., 2017.

http:www.uel.br/revistas/informacao/ 
Fabio Assis Pinho

Percurso investigativo para contextualização de metáforas relativas à gênero e sexualidade em linguagens documentais

Notou-se, então, que a identificação da terminologia está diretamente relacionada à natureza e aos propósitos da comunidade discursiva. Nas pesquisas mencionadas, as linguagens documentais brasileiras analisadas não foram suficientemente precisas em relação à representação da temática da homossexualidade masculina, especialmente porque tal assunto não está devidamente estruturado nessas linguagens. $O$ fato é que a homossexualidade foi tratada pela sociedade de forma periférica, isto é, às margens e, por vezes, como desvio moral. Isso, de certa forma, reforça a visão preconceituosa que se tem sobre a essa comunidade discursiva e, consequentemente, sobre sua terminologia.

Nesse sentido, foi perceptível que a coleção de palavras-chave oriundas das revistas permitiria uma variedade de análises. Não obstante, percebeu-se que o objetivo geral deste trabalho começou a ser atingido a partir do procedimento de coleta das palavras-chave nas revistas especializadas, pois essas palavras estariam amparadas pela garantia literária e pelo uso científico que se faz delas.

A partir da coleta dessas palavras-chave, compreendeu-se, então, que de um lado têm-se comunidades discursivas que se caracterizam por pessoas com objetivos em comum e, de outro lado, processos e produtos da organização e representação da informação e do conhecimento que, por sua vez, são redutores de carga semântica para viabilizar a recuperação da informação. Esse desafio se tornou evidente no âmbito do estudo da representação do conhecimento na temática da homossexualidade masculina. Primeiro porque se notou no percurso investigativo uma alta presença de metáforas por parte dessa comunidade discursiva e, segundo, que essas metáforas reafirmam a identidade dos sujeitos pertencentes a essa comunidade.

A presença constante de figuras de linguagem (metáforas) e de palavras que refletiam a identidade da comunidade discursiva destacou-se fortemente. Por conta disso, para que essas metáforas façam parte de instrumentos e processos de organização do conhecimento para tal comunidade discursiva

Inf. Inf., Londrina, v. 22, n. 2, p. 117 - 143, maio/ago., 2017. http:www.uel.br/revistas/informacao/ 
Fabio Assis Pinho

Percurso investigativo para contextualização de metáforas relativas à gênero e sexualidade em linguagens documentais

faz-se necessário sua contextualização e não apenas a restrição da sua carga semântica.

A partir desta constatação, as investigações seguintes contemplaram a identificação dos termos a partir da literatura científica e permitiram as explicações sobre a evolução dos conceitos, bem como, a forma como se relacionam. No âmbito da homossexualidade isso foi importante, porque permitiu uma reflexão sobre a evolução com a qual a sociedade entende a homossexualidade, nesse caso a masculina. Nesse quesito, é importante notar como a organização e representação da informação e do conhecimento podem contribuir para os estudos de memória no âmbito da Ciência da Informação.

E onde residiu a importância dessa fase no percurso investigativo? Sabe-se que o profissional da informação identifica e seleciona termos em detrimento de outros. Ele identifica aqueles que melhor representem e expressem o conteúdo do documento e, para isso, realiza leituras profissionais que são permeadas pelos movimentos cognitivos de top-down e bottom-up. Todavia apesar de dominar os procedimentos, o sistema não é previsível, visto que não é fechado. O mundo das escolhas é um sistema aberto, que sofre influências do meio externo e interno. Isso é possível visto a interação incessante de seus elementos e, por esse e outros motivos, entende-se que algumas atividades da organização do conhecimento são subjetivas. Nesse sentido, todos os elementos que circundam o universo desse profissional, acabaram por influenciar seu comportamento, suas reações e suas escolhas.

Sabendo dessa participação efetiva do meio e sua influência em nossas atitudes compreende-se que a nossa bagagem cultural afeta diretamente toda e quaisquer tomada de decisão. Sendo assim, ao realizarmos qualquer tipo de escolha vamos além das técnicas e dos métodos que dominamos, pois vamos nos valer de nossa construção sócio-político-cultural. Nesse espectro nos deparamos com o mito da neutralidade, da imparcialidade.

Para isso torna-se necessário que o indexador ou o profissional da informação possua habilidades e competências além daquelas inerentes ao tratamento da informação como, por exemplo, a noção de sua relação com o

Inf. Inf., Londrina, v. 22, n. 2, p. 117 - 143, maio/ago., 2017.

http:www.uel.br/revistas/informacao/ 
Fabio Assis Pinho

Percurso investigativo para contextualização de metáforas relativas à gênero e sexualidade em linguagens documentais

documento e de que outros irão a algum momento buscar, recuperar e absorver essas informações, dando continuidade assim ao ciclo informacional. E para que este ciclo seja mantido, todos devem ter seus interesses atendidos ou suas necessidades supridas. E para que isso ocorra, torna-se necessário que o usuário final se identifique e se sinta representado naquele produto da representação do conhecimento. Sendo necessário que o profissional da informação tenha convicção de que seus atos podem e estão imbuídos de seus conceitos, seus pré-conceitos e que atuam diretamente em sua produção.

Nesse sentido, na pesquisa mencionada verificou-se que após a identificação, coleta e análise das palavras-chaves, iniciou-se uma organização conceitual para que essa base léxica resultasse em um produto documental. As palavras-chave que foram consideradas relevantes para o estudo foram as de incidência igual ou maior que dez repetições. Posteriormente, foram identificadas e conceituadas as que continham representação metafórica. Logo em seguida foi realizada a categorização a partir da classificação multifacetada de Ranganathan, que objetiva a estruturação do conhecimento, por meio da organização dos conceitos $\mathrm{e}$ das relações entre eles, permitindo o mapeamento de uma área de assunto e a inclusão de novos conceitos. Essa categorização possibilitou que palavras de diferentes aspectos possam ser organizadas simultaneamente de acordo com as facetas/categorias do PMEST (Personalidade, Matéria, Energia, Espaço e Tempo) de Ranganathan (1985).

\section{RESULTADOS EM CURSO}

A coleção de palavras-chave, nessa fase do percurso, contava com um total de 1.962 (um mil novecentos e sessenta e duas) palavras, das quais se levaram em consideração apenas as palavras que tiveram sua incidência igual ou superior a 10 (dez) vezes de repetição. Após efetuar o recurso da incidência, as palavras foram analisadas no intuito de verificar se eram de fato exclusivas do universo da homossexualidade masculina. Após esses procedimentos, chegou-se à quantidade de 51 (cinquenta e uma) palavras e, dentre elas, foram encontradas 12 metáforas oriundas da literatura científica,

Inf. Inf., Londrina, v. 22, n. 2, p. 117 - 143, maio/ago., 2017.

http:www.uel.br/revistas/informacao/ 
Fabio Assis Pinho

Percurso investigativo para contextualização de metáforas relativas à gênero e sexualidade em linguagens documentais

que foram: closet (armário), coming out (assumir-se), bareback (sexo sem preservativo), leather (couro), cruising (caçar), dogging (banheirão), fag hag (mulher amiga do homossexual), chicken (homossexual jovem), dude (lolito), don't ask, don't talk (não pergunte, não fale), bears (ursos) e queer (bicha).

Quadro 1: Exemplo dos 51 Termos Coletados e Categorizados pelo PMEST.

\begin{tabular}{c|c|c}
\hline Bissexualidade & Clubes de strip & Comportamento sexual \\
\hline Homens bissexuais & Acompanhates & Sexo anal \\
\hline Bissexuais & Agência & Ansiedade de separação \\
\hline Bissexual & Agência sexual & Comportamento do mesmo \\
sexo
\end{tabular}

Fonte: Elaborado pelo autor.

Inf. Inf., Londrina, v. 22, n. 2, p. 117 - 143, maio/ago., 2017. http:www.uel.br/revistas/informacao/ 
Após a coleta e categorização das palavras, foi necessário confirmá-las por meio das garantias literária e de usuário, isto é, se essas palavras são usadas nas produções da comunidade discursiva (além da científica) e faladas por seus participantes.

É importante salientar que a tradução dos termos do Inglês para a Português foi resolvida com a adoção de dois dicionários especializados, a saber: "The guild dictionary of homosexual terms" de autoria do Dr. Albert Ellis (c1965) e o "Reader's guide to lesbian and gay studies" cujo editor é Timothy F. Murphy (2000). Após consulta a essas obras de referência, os termos foram comparados em livros de temática homossexual como, por exemplo, romances e estudos gerais e científicos. Esses livros compõem a coleção particular do bibliotecário e professor aposentado Edson Nery da Fonseca (in memoriam). Nessa perspectiva, a presença das 51 palavras foi recorrente nesses livros, por conta disso, foi possível conseguir a garantia literária por meio de uma boa cobertura bibliográfica (BARITÉ et al., 2010).

Para conseguir a garantia do usuário para a análise desses doze termos metafóricos, confeccionou-se um formulário para ser apresentado aos gestores de entidades representativas de homossexuais, conforme demonstra o Quadro 2 a seguir.

Quadro 2: Modelo do formulário apresentado aos gestores de entidades representativas dos homossexuais.

TERMO:

Inf. Inf., Londrina, v. 22, n. 2, p. 117 - 143, maio/ago., 2017. http:www.uel.br/revistas/informacao/ 


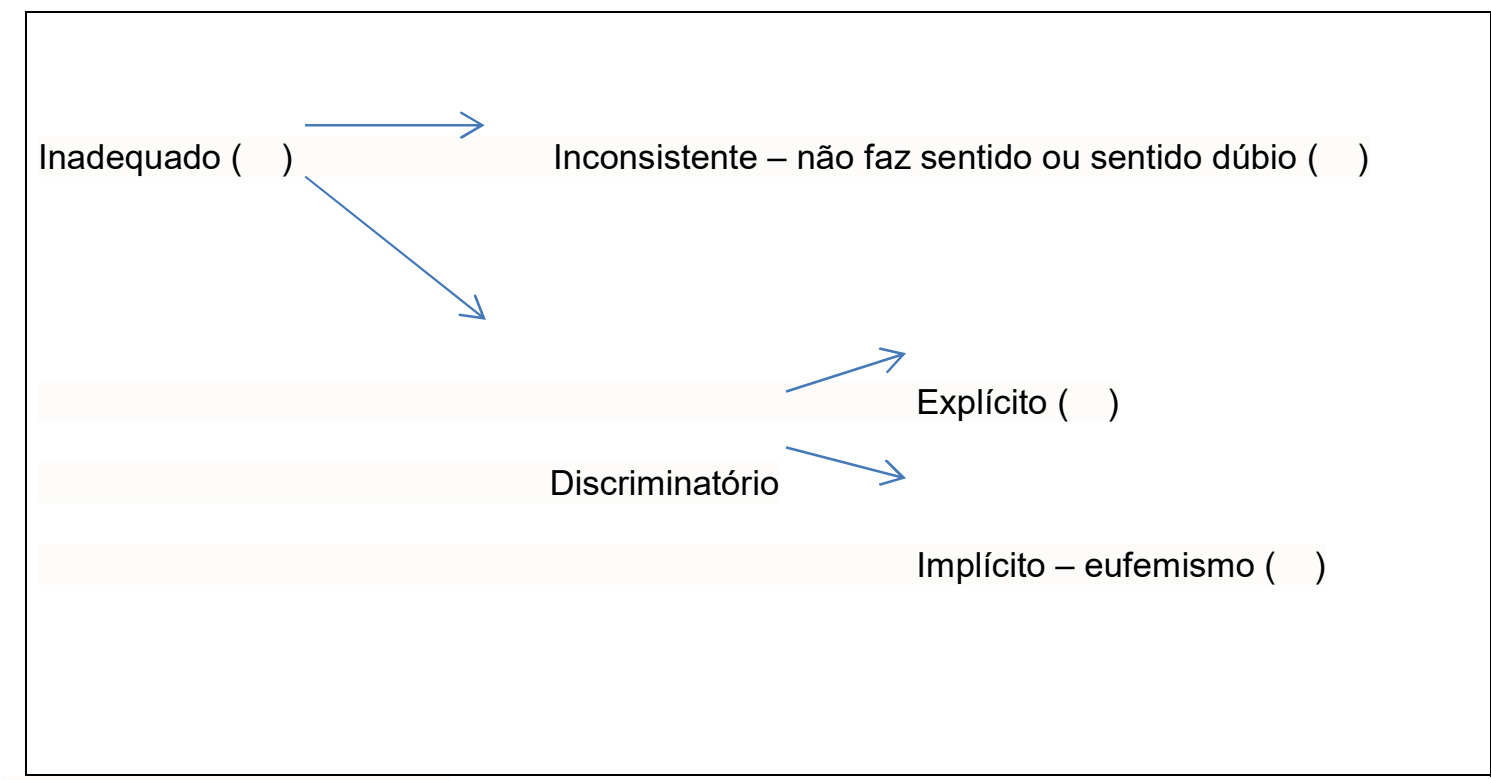

Fonte: Elaborado pelo autor.

Após a estruturação do formulário, foram identificadas as entidades representativas dos homossexuais e os 8 (oito) gestores dessas entidades, com os quais foram feitos posteriores contatos (telefonemas e trocas de emails, sendo marcadas visitas presenciais) a fim de expor e propor sua participação na pesquisa. Nessas visitas, foram entregues os formulários com os doze termos metafóricos, os quais foram recolhidos num prazo de 30 dias.

As entidades contatadas foram: Núcleo de Pesquisa em Gênero e Masculinidades da Universidade Federal de Pernambuco (GEMA - UFPE), que está vinculado ao Programa de Pós-Graduação em Psicologia da UFPE, inscrito no Diretório de Grupos de Pesquisa do CNPq desde 1998; Instituto PAPAI, que é uma ONG que atua a partir da perspectiva feminista de gênero, atuando prioritariamente com homens e sobre masculinidades, contra todas as expressões do machismo; e a Confraria Ursos de Pernambuco, que é uma casa que reúne homossexuais regularmente a fim de promover diversão noturna. Veja no quadro a seguir um exemplo de como os dados foram tabulados em relação a um dos termos metafóricos analisados pelos representantes a fim de obter a garantia de usuário.

Inf. Inf., Londrina, v. 22, n. 2, p. 117 - 143, maio/ago., 2017. http:www.uel.br/revistas/informacao/ 
Quadro 3: Exemplo da tabulação do termo "bareback" para a garantia do usuário.

Fonte: Elaborado pelo autor.

Sobre esse exemplo, especificamente, detectou-se que a inconsistência encontrada se relaciona ao sentido dúbio do termo, pois na perspectiva da homossexualidade o termo corresponde ao significado, porém, mudando-se a comunidade discursiva, o termo "frango" adquire outra significação. Por exemplo, envolvendo pessoas que se exercitam fisicamente, pode designar aquele que começou a se exercitar recentemente, o "fraco/magro/pequeno".

Três pesquisadores sugeriram que, em inglês, o termo "faggot" é mais adequado. Dois deles consideraram o termo adequado (mas um deles explicou que não se refere apenas aos jovens), e o terceiro o considerou inconsistente. Um dos pesquisadores relacionou a discriminação explícita à ofensa a homens gays e/ou afeminados. Contudo, explicou que também é usado dentro da comunidade homossexual sem ser discriminatório.

Inf. Inf., Londrina, v. 22, n. 2, p. 117 - 143, maio/ago., 2017. http:www.uel.br/revistas/informacao/ 
O pesquisado que declarou como discriminatório implícito explicou que o termo é pejorativo e depreciativo, mas por vezes é usado pela comunidade homossexual ironicamente, de forma a evidenciar a discriminação. Já o pesquisado que considerou o termo pouco específico explicou que só se refere ao homossexual no nordeste brasileiro, não se podendo generalizar o termo, além disso, não se refere apenas ao homossexual, mas também à falta de virilidade, ligando à feminilidade.

Logo, para que um domínio seja bem representado em sistemas de informação, tanto a garantia literária (HULME, 1911, 1912) quanto a garantia de usuário são necessárias, esta última, especialmente, permite ao profissional da informação compreender que aqueles termos realmente compreendem o grupo ao qual busca representar, e, assim, devem ser utilizados em instrumentos de organização do conhecimento. À vista disso, as entidades representativas dos homossexuais e seus gestores foram escolhidos a fim de representar os usuários desse domínio, tendo em vista a relação direta e diária dessas instituições com a área estudada; as metáforas apresentadas aos gestores foram analisadas uma a uma, para que assim se pudesse realizar a etapa de verificação da adequação das mesmas.

Ressalta-se que as fases de categorização, tradução e busca por consolidação das garantias contribuíram efetivamente para atingir o objetivo geral deste trabalho, pois essas fases permitiam a compreensão da metodologia para a contextualização das metáforas.

\section{$4 \quad$ ANÁLISES E DISCUSSÕES}

Desde o processo de coleta das palavras-chave nas revistas científicas especializadas, a maneira contextualizadora com que elas foram traduzidas para a Língua Portuguesa, bem como a sua categorização a partir do PMEST de Ranganathan possibilitaram que as próximas etapas investigativas fossem colocadas em prática, a saber: aplicação do metafiltro, a construção de mapas conceituais e a tentativa de construção de uma linguagem documental.

Inf. Inf., Londrina, v. 22, n. 2, p. 117 - 143, maio/ago., 2017. http:www.uel.br/revistas/informacao/ 
A partir desse momento foi necessário refletir sobre as questões identificadas e relacionadas à complexidade de um termo metafórico e sua necessária contextualização para inclusão em linguagens documentais. Não obstante e com o intuito de fortalecer as garantias literária e de usuário, tornou-se possível aplicar o metafiltro em comparação com as categorias de Ranganathan.

Isso porque as metáforas supracitadas foram submetidas a categorizações com base no metafiltro proposto por Orrico (2001), cujo fundamento da autora se baseia nos estudos feitos por Ranganathan e sua classificação multifacetada, a qual objetiva a estruturação do conhecimento, por meio da organização dos conceitos e das relações entre eles, permitindo o mapeamento de uma área de assunto e a inclusão de novos conceitos. Então, com base no metafiltro proposto por Orrico (2001) é possível classificar semanticamente os termos por meio da Essência, da Função e do Modo.

A categorização dos termos nesse percurso da pesquisa se justifica por encontrar na teoria da comunicação a existência de ruídos comunicacionais, isto é, o distanciamento do usuário para com as informações buscadas, tornando acessível e facilitando a busca por informações ligadas ao domínio temático da homossexualidade, especialmente quando do uso de metáforas sua contribuição se dá na busca pela diminuição ou até mesmo extinção dessa falésia, pois a partir do momento em que for estabelecido um vocabulário controlado que norteie a classificação da temática homossexual, seus usuários irão se sentir representados, possibilitando com isto a criação de novos conhecimentos. Além disso, também possibilita o reconhecimento do usuário dentro deste universo temático, legitimando a sua identidade, evitando, assim, a perpetuação de biases (bias, numa tradução literal, significa alijamento, afastamento, segregação, exclusão) a partir de uma classificação eticamente aceitável.

Nessa fase, identificou-se que as figuras de linguagem nessa comunidade discursiva contribuem para a construção da sua identidade, ou seja, as metáforas e os eufemismos, por exemplo, estabelecem relações entre as esferas de significação e, dessa forma, auxiliarão na construção da

Inf. Inf., Londrina, v. 22, n. 2, p. 117 - 143, maio/ago., 2017. http:www.uel.br/revistas/informacao/ 
identidade desse grupo, ou seja, é no discurso dessa comunidade que essas figuras de linguagem ganham significados (ORRICO, 2001).

Essas análises encontraram respaldo na visão de Orrico (2001), que sugere que:

$\mathrm{Na}$ tentativa de estabelecer as bases sintáticas do elo semântico do enunciado e depreender as metáforas, optamos por trabalhar com as sentenças em que o verbo ser é explicado ou não deixa margem à dúvida quanto à possibilidade de sua presença, ou ainda por verbo que indica a relação de semelhança, como por exemplo, representar (ORRICO, 2001, p. 144, grifo nosso).

De acordo com o exposto, cada um dos termos mencionados anteriormente representam uma questão de cunho metafórico ou eufemístico e todos eles foram submetidos às etapas e aos testes de adequação e aplicação do metafiltro. As categorias S (espaço) e T (tempo) do "PMEST", de Ranganathan, não foram analisadas, visto que as metáforas podem possuir uma significação em certa comunidade discursiva e outra significação em outra comunidade discursiva. Assim como não se pode precisar por quanto tempo uma metáfora permanecerá compreendendo determinado significado.

Sendo assim, um exemplo da categorização com o uso do metafiltro está apresentado no quadro a seguir.

Quadro 4: Exemplo de Enquadramento do Termo Metafórico com o PMEST e o Metafiltro

\begin{tabular}{|c|l|l|l|}
\hline TERMO & PMEST & METAFILTRO & RESULTADO \\
\hline & $\begin{array}{l}\text { Personalidade } \\
\text { (Enuncia ossência } \\
\text { discurso quem } \\
\text { é) }\end{array}$ & $\begin{array}{l}\text { Aquele que assume } \\
\text { sua orientação sexual }\end{array}$ \\
\cline { 2 - 4 } $\begin{array}{c}\text { Sair do Armário ou } \\
\text { Assumir-se } \\
\text { (Coming out) }\end{array}$ & $\begin{array}{l}\text { Matéria } \\
\text { (Conseguir o } \\
\text { produto final - o } \\
\text { que faz) }\end{array}$ & Função & $\begin{array}{l}\text { Assume sua } \\
\text { orientação sexual }\end{array}$ \\
\cline { 2 - 4 } & $\begin{array}{l}\text { Energia } \\
\text { (Manifesta nas } \\
\text { atividades } \\
\text { como faz) }\end{array}$ & Modo ou Condição & $\begin{array}{l}\text { Revelando } \\
\text { publicamente sua } \\
\text { orientação sexual }\end{array}$ \\
\hline
\end{tabular}

Fonte: Elaborado pelo autor.

Inf. Inf., Londrina, v. 22, n. 2, p. 117 - 143, maio/ago., 2017. http:www.uel.br/revistas/informacao/ 
No exemplo anterior tem-se que assumir-se (Coming out, em inglês) é uma metáfora para o ato de sair do armário, ou seja, assumir publicamente sua orientação sexual.

Em consequência do levantamento, tradução e conceituação das palavras-chave e após sua categorização de acordo com o PMEST e a aplicação do metafiltro, foi possível produzir mapas conceituais para compreender as relações de contextualização entre as metáforas e, a partir disso, relacioná-las para que sejam inseridas em linguagens documentais.

A teoria dos mapas conceituais foi desenvolvida na década de 1970 pelo pesquisador Joseph Novak, com base na teoria da aprendizagem significativa. Segundo o pesquisador, mapa conceitual é uma ferramenta para organizar e representar o conhecimento (NOVAK, 1980). Os conceitos aparecem dentro de caixas e as relações entre eles são especificadas por meio de frases de ligação que unem cada um dos conceitos.

Existem basicamente quatro tipos de mapas, tais como: mapa conceitual do tipo teia de aranha, mapa conceitual tipo fluxograma, mapa conceitual tipo sistema: entrada e saída e o mapa conceitual hierárquico. Para o mapa conceitual em questão, foi escolhido o modo "entrada e saída", cuja informação é apresentada numa ordem ligando os conceitos pelas suas possibilidades de interação, por onde a informação que irá nortear todas as ligações dos termos foi colocada em sua parte superior.

O software utilizado foi o CMap Tools, que está disponível para download gratuitamente na internet, no site http://cmap.ihmc.us. O conjunto de ferramentas permite que qualquer pessoa que possua interesse, construa mapas conceituais e compartilhe o conhecimento expresso em seus mapas com outras pessoas. O sistema possui muitas facilidades para o processo de construção de mapas. Permite, por exemplo, que estes sejam construídos individualmente ou como parte de uma construção coletiva. Podem ser enviados por meio eletrônico ou publicados em servidores para apreciação de qualquer um que possua um acesso à internet. A versão utilizada para a produção do mapa foi a 6.01, o software foi baixado e instalado de maneira gratuita, em sua versão teste, norteando a pesquisa e atendendo de forma

Inf. Inf., Londrina, v. 22, n. 2, p. 117 - 143, maio/ago., 2017. http:www.uel.br/revistas/informacao/ 
Fabio Assis Pinho

Percurso investigativo para contextualização de metáforas relativas à gênero e sexualidade em linguagens documentais

plena aos requisitos necessários para a construção do mapa conceitual a partir de domínio estudado.

Dessa forma, as metáforas foram inseridas no software com o intuito de compreendê-las em seu sentido polissêmico. Essa visualização por meio do mapa conceitual auxiliou na compreensão dos termos e como eles são utilizados pela comunidade discursiva em questão, conforme demonstram as figuras 1 e 2 a seguir.

Figura 1: Outline do CMapTools demonstrando as relações entre os termos metafóricos.

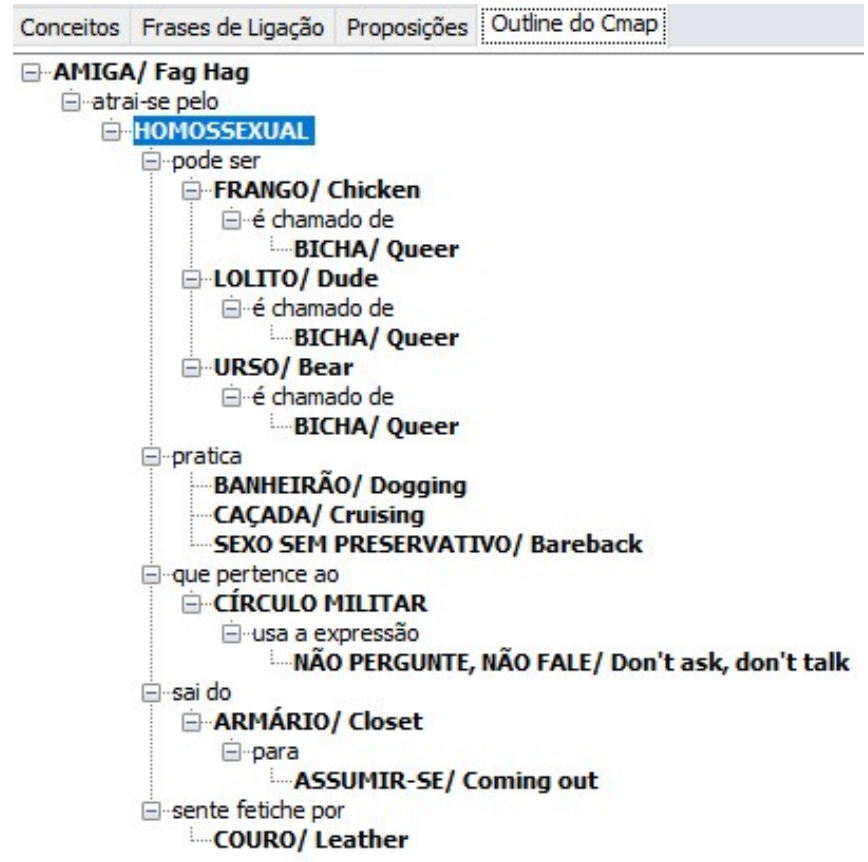

Fonte: Elaborado pelo autor.

Inf. Inf., Londrina, v. 22, n. 2, p. 117 - 143, maio/ago., 2017.

http:www.uel.br/revistas/informacao/ 
Figura 2: Mapa conceitual com as metáforas analisadas - CMap Tools.

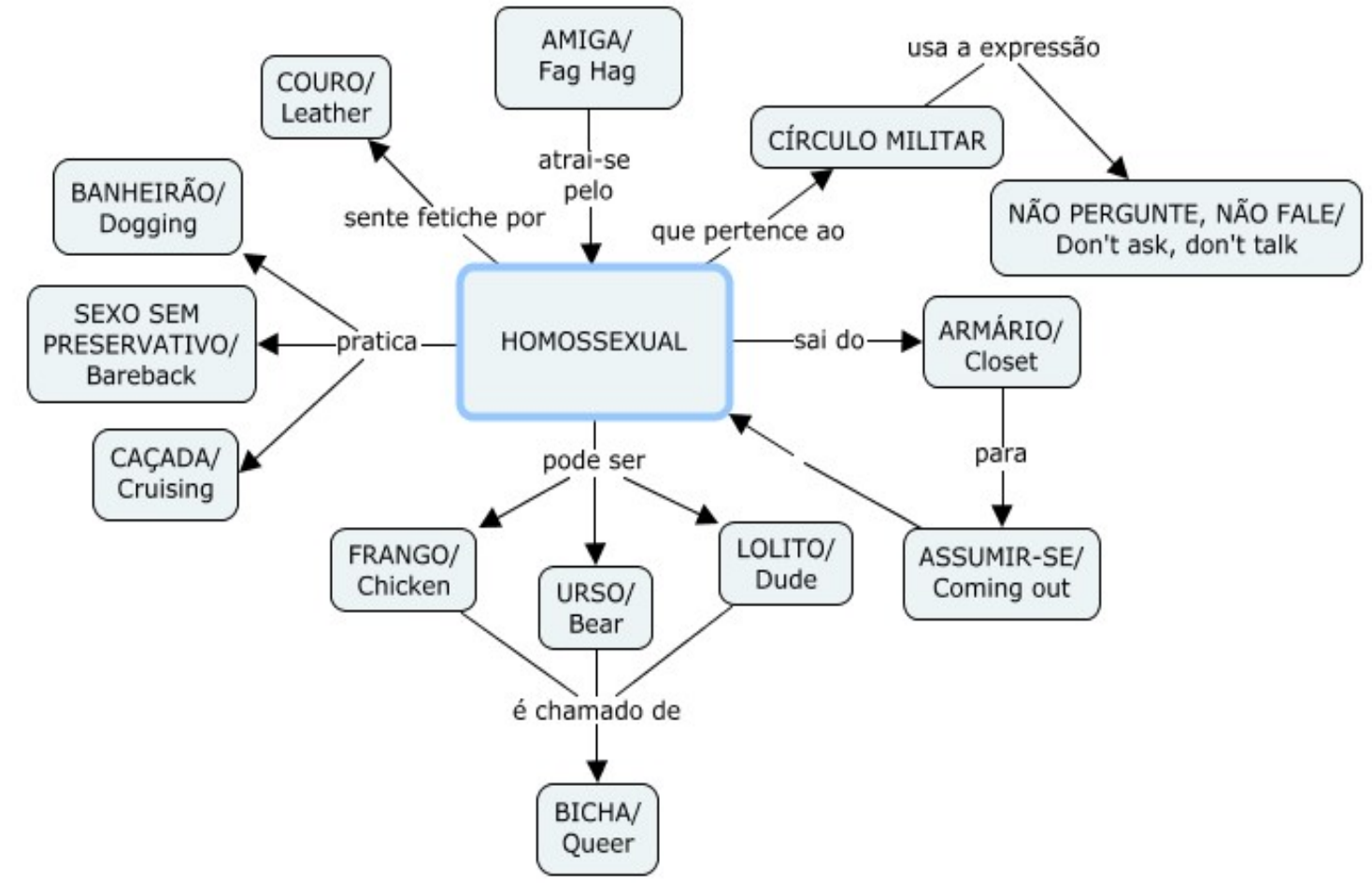

Fonte: Elaborado pelo autor.

De acordo com a relação dos termos, tem-se inicialmente a metáfora "Amiga/Fag Hag", cujo conteúdo se conecta a "homossexual" pela atração que existe por sua parte, usando-se a ação "atrai-se pelo". O conceito "Fag hag" foi compreendido não apenas pela relação de amizade existente entre o homossexual e a amiga, mas também pelo desejo dela por ele.

O conceito "Homossexual" é central para a construção do mapa conceitual, pois se trata de um conceito mais genérico e que a ele todos os demais se relacionam. A princípio identificaram-se termos metafóricos que representam práticas sexuais de homossexuais, tais como: "Banheirão/Dogging", "Sexo sem preservativo/Bareback" e "Caçada/Cruising". Dessa forma, a ação utilizada para a ligação desses termos foi materializada pelo verbo "pratica".

A metáfora "Couro/Leather" foi identificada como um fetiche sexual nessa comunidade discursiva. Por isso, a ligação entre os termos se deu pela ação de "sente fetiche por", ou seja, é um elemento de desejo.

Inf. Inf., Londrina, v. 22, n. 2, p. 117 - 143, maio/ago., 2017.

http:www.uel.br/revistas/informacao/ 
Além disso, identificou-se que a comunidade homossexual identifica-se por meio de metáforas que expressam características físicas, tais como: "Frango/Chicken", "Urso/Bear" e Lolito/Dude". Podemos entender como subgrupos inseridos no grupo "Homossexual". Nesse sentido, a ação que mais se aproximou para estabelecer a relação foi o uso de "pode ser", ou seja, um homossexual pode ser considerado um frango ou um urso ou um lolito, por exemplo. E todos esses subgrupos podem ser chamados de "Bicha/Queer", pois esse termo é amplo e pode ser usado de maneira eufemística.

Percebeu-se também, na coleta dos termos metafóricos, que o homossexual nem sempre revela ou divulga sua orientação sexual por tratar-se de uma questão de foro íntimo. Assim, identificaram-se duas metáforas que representam quando um homossexual revela sua orientação sexual, a saber: "Armário/Closet" e "Assumir-se/Coming out".

Identificou-se, também, uma metáfora específica para homossexuais que atuam no círculo militar, a saber: "Não pergunte, não fale/don't ask, don't talk". Essa metáfora é utilizada para expressar um assunto tabu dentro de um ambiente profissional específico.

O mapa conceitual elaborado permitiu a continuidade da pesquisa e, principalmente, na compreensão dos termos metafóricos e a forma como eles podem ser usados em produtos documentais para recuperação da informação. Portanto, verificou-se que a perda da carga semântica não seria satisfatória para compreender a metáfora no âmbito da linguagem documental e, sim, a sua contextualização.

Por isso, a partir do mapa conceitual foram propostas, então, algumas entradas para compor um protótipo de uma linguagem documental para a homossexualidade masculina. Veja o exemplo da cadeia e do renque, a seguir:

\section{HOMOSSEXUAL}

NE: Indivíduo cuja relação e prática afetiva se manifesta por indivíduo do mesmo sexo.

Inf. Inf., Londrina, v. 22, n. 2, p. 117 - 143, maio/ago., 2017.

http:www.uel.br/revistas/informacao/ 

TE: Frango
TE: Lolito
TE: Urso
TA: Amiga
TA: Armário
TA: Assumir-se
TA: Banheirão
TA: Caçada
TA: Sexo sem preservativo
UP: Bicha

$\mathrm{Na}$ cadeia e renque exemplificado anteriormente, tem-se a materialização de relações lógicas e ontológicas. As relações de subordinação lógica se manifestam quando a intenção do conceito subordinado inclui a intenção do conceito superordenado, além de uma característica especificadora. Os conceitos Frango, Lolito e Urso possuem características especificadoras do conceito superordenado homossexual.

As relações ontológicas são materializadas pelo fato de que os conceitos se relacionam por contiguidade no tempo e no espaço e por facetas como, por exemplo, em Amiga, Armário, Assumir-se, Banheirão, Caçada e Sexo sem preservativo.

Outra relação que se estabeleceu foi a relação entre os termos. Nesse caso, homossexual e bicha se relacionam por metáfora sendo o primeiro o preferido.

Até esse momento, têm-se resultados interessantes que se confirmaram a partir de um conjunto de reflexões teórica e metodológica, ou seja, a forma da coleta das palavras-chaves, a tradução, a categorização com o uso do PMEST, a aplicação do metafiltro, a construção de mapas conceituais e o protótipo de construção de uma linguagem documental revelou a construção de um percurso investigativo e a materialização de uma linha de pesquisa para a organização e representação da informação e do conhecimento. As propostas metodológicas, os temas e as teorias são aglutinadores e, por isso, guardam afinidades entre si. Outros estudos podem ser conduzidos a por conta dessa aglutinação e afinidade temática tornando-se uma linha de pesquisa. Esse

Inf. Inf., Londrina, v. 22, n. 2, p. 117 - 143, maio/ago., 2017.

http:www.uel.br/revistas/informacao/ 
Fabio Assis Pinho

Percurso investigativo para contextualização de metáforas relativas à gênero e sexualidade em linguagens documentais

percurso investigativo demonstrou isso. Assim, outros temas e descobertas vão se aglutinando.

Essa aglutinação foi verificada quando a questão metafórica pareceu próxima de uma possível solução para a sua inserção em linguagens documentais.

Outros termos surgiram e foram considerados "fronteiriços" na questão de gênero, especialmente porque são variantes de gênero não binários. O uso da palavra "fronteiriço" entre aspas é empregado pelo fato de que os termos encontrados não se enquadram de forma canônica na dicotomia aristotélica e também pelo fato de que eles não encontram classes únicas se forem inseridos em linguagens documentais como, por exemplo, ao formar cadeias ou renques. Nesse sentido, um termo "fronteiriço" carrega consigo características epistêmicas de vários conceitos. Por exemplo: gênero pode ser definido como uma característica que identifica ou diferencia homens e mulheres. Dessa forma, em um tesauro, os conceitos de homem e mulher carregam consigo, em uma relação de subordinação lógica, a intenção do conceito superordenado gênero. Entretanto, esse mesmo exercício não pode ser aplicado para conceitos como: bigênero, intergênero ou terceiro gênero, pois, eles carregam características epistêmicas de dois ou mais conceitos e, por isso, considerados "fronteiriços". De forma análoga, bigênero não apenas identifica ou diferencia homens e mulheres, mas os dois conjuntamente.

Nesse sentido, foram identificados 35 (trinta e cinco) termos que se enquadram nessa fronteira, foram eles: agender, aliagender, ambigender, androgine, bigender (female-male), butch non-binary, cristaline, demigender, denboy, demigirl, efemere, femme non-binary, genderfluid (female-male), genderflux, genderfuck, genderpivot, genderqueer non-binary, graygender, male non-binary, intergender ou intersex, female non-binary, nan0gender, nan0boy, nan0girl, nan0-menine, negative, neutrois, pangender, poligender, positive, third gender, transfemale ou male to female, transfemale ou female to male, travestite non-binary e trigender.

Inf. Inf., Londrina, v. 22, n. 2, p. 117 - 143, maio/ago., 2017. http:www.uel.br/revistas/informacao/ 
Isso demonstra que, dada a natureza marginal de algumas práticas sexuais em relação aos padrões sociais atuais, esses termos tornam-se "fronteiriços" em relação à questão de gênero. Por conta disso, algumas questões emergiram: há alguma maneira de ligar a questão da materialidade do corpo com a performatividade de gênero? Como a categoria sexo figura nas linguagens documentais? $O$ fato é que muitas pesquisas são necessárias para responder essas e outras questões que irão surgir.

\section{$5 \quad$ BREVES CONSIDERAÇÕES FINAIS}

Responder a essas perguntas instiga ainda mais esse percurso investigativo e a literatura que trata dessa temática tem sido cada vez mais profícua como, por exemplo, é possível verificar em Olson (1998), Bowker e Star (1999), Olson (2002, 2003), Keilty (2009), Milani (2010), Keilty e Dean (2013), Fox (2016), Keilty e Smiraglia (2016), Adler (2017) entre outros.

Além disso, cabe mencionar as edições do Colóquio sobre Gênero e Sexualidade em Estudos de Informação, em 2014 na Universidade de Toronto e, em 2016, na Universidade Simon Fraser, em Vancouver, ambas no Canadá que produziram profícuos artigos sobre organização da informação e gênero.

Assim, a guisa de conclusão percebe-se que a reflexão teórica e metodológica a respeito do percurso investigativo sobre metáforas relativas a gênero e sexualidade em linguagens documentais se mostrou profícua para compreender e contextualizar termos metafóricos pertencentes a uma determinada comunidade discursiva e que dizem respeito a gênero e sexualidade. Apesar das metáforas serem polissêmicas, a contextualização e aplicação do metafiltro se mostrou efetiva para tornar esses termos candidatos a descritores seja para a atividade de indexação ou para ingressar em linguagens documentais.

Além disso, a reflexão sobre as teorias e as metodologias aplicadas permitiu vislumbrar a materialização de uma linha pesquisa a partir da

Inf. Inf., Londrina, v. 22, n. 2, p. 117 - 143, maio/ago., 2017. http:www.uel.br/revistas/informacao/ 
aglutinação de temas e métodos com afinidades, bem como a continuidade dessas reflexões.

Portanto, essa reflexão sobre o percurso investigativo para contextualização de metáforas promove não apenas uma visão geral, mas possíveis tendências e desafios para futuras pesquisas em organização e representação da informação e do conhecimento e a questão de gênero e sexualidade.

\section{REFERÊNCIAS}

ADLER, M. Cruising the library: perversities in the organization of knowledge. Bronx: Fordham University Press, 2017. 232 p.

BARITÉ, M. et. al. Garantia literária: elementos para uma revisão crítica após um século. TransInformação, Campinas, v. 22, n. 2, p. 123-138, 2010.

BOWKER, G. C.; STAR, S. L. Sorting things out: classification and its consequences. Cambridge: MIT Press, 1999. 377p.

DAHLBERG, I. Ethics and knowledge organization: in memory of Dr. S. R. Ranganathan in his centenary year. International Classification, Frankfurt, v. 19, n. 1, p. 1-2, 1992.

ELLIS, A. The guild dictionary of homosexual terms. Washington: Guild Press Ltd., c1965.

FOX, M. J. Legal discourse's epistemic interplay with sex and gender classification in the Dewey Decimal Classification System. Library Trends, Champaign, v. 64, n. 4, p. 687-713, 2016.

GUIMARÃES, J. A. C.; PINHO, F. A. Aspectos éticos em organização e representação do conhecimento (O.R.C.). In: ENCONTRO NACIONAL DE PESQUISA EM CIÊNCIA DA INFORMAÇÃO, 7., 2006, Marília. A dimensão epistemológica da Ciência da Informação e suas interfaces técnicas, políticas $\mathrm{e}$ institucionais nos processos de produção acesso e disseminação da informação. Marília: UNESP, 2006.

Inf. Inf., Londrina, v. 22, n. 2, p. 117 - 143, maio/ago., 2017. http:www.uel.br/revistas/informacao/ 
GUIMARÃES, J. A. C.; PINHO, F. A. Aspectos éticos em organização e representação do conhecimento (O.R.C.). In: FUJITA, M. S. L.; MARTELETO, R. M.; LARA, M. L. G.. (Org.). A dimensão epistemológica da Ciência da Informação e suas interfaces técnicas, políticas e institucionais nos processos de produção, acesso e disseminação da informação. São Paulo: Cultura Acadêmica, 2008. p. 67-86.

GUIMARÃES, J. A. C.; PINHO, F. A.; CANDIDO, G. G.; MOTA, B. G. Gay marriage and homo-affective union: a terminological analysis of the social values of libraries as a source for an ethical subject representation and dissemination in Brazil. In: WORLD LIBRARY AND INFORMATION CONGRESS: 80th IFLA GENERAL CONFERENCE AND ASSEMBLY, 2014, Lyon. Libraries, Citizens Societies: Confluence for Knowledge. Haia: IFLA, 2014. p. 1-10.

GUIMARÃES, J. A. C.; PINHO, F. A.; MILANI, S. O. Theoretical dialogs about ethical issues in Knowledge Organization: García Gutiérrez, Hudon, Beghtol, and Olson. Knowledge Organization, v. 43, p. 338-350, 2016.

HULME, E. W. Principles of book classification. Library Association Record, London, v. 13, p. 354-358, 1911.

HULME, E. W. Principles of book classification. Library Association Record, London, v. 14, p. 39-46, 1912.

KEILTY, P. Tabuling queer: space, perversion, and belonging. Knowledge Organization, Würzburg, v. 36, n. 4, p. 240-248, 2009.

KEILTY, P.; DEAN, R. (Ed.). Feminist and queer information studies reader. Sacramento: Litwin Books, 2013. 700 p.

KEILTY, P.; SMIRAGLIA, R. Gay male nomenclature. In: GUIMARÃES, J. A. C.; MILANI, S. O.; DODEBEI, V. (Org.). Knowledge organization for a sustainable world: challenges and perspectives for cultural, scientific, and technological sharing in a connected society. WÜrzburg: Ergon Verlag, 2016. p. 579-586.

ORRICO, E. G. D. Binômio Linguística-Ciência da Informação: abordagem teórica para elaboração de metafiltro de recuperação da informação. 2001. 206 p. Tese (Doutorado em Ciência da Informação) - Instituto Brasileiro de Informação em Ciência e Tecnologia / Universidade Federal do Rio de Janeiro, Rio de Janeiro.

MARTíNEZ-ÁVILA, D.; GUIMARÃES, J. A. C.; PINHO, F. A. ; FOX, M. J. The representation of ethics and knowledge organization in the WoS and LISTA databases. Knowledge Organization, v. 42, p. 269-275, 2015.

Inf. Inf., Londrina, v. 22, n. 2, p. 117 - 143, maio/ago., 2017. http:www.uel.br/revistas/informacao/ 
MILANI, S. O. Estudos éticos em representação do conhecimento: uma análise da questão feminina em linguagens documentais brasileiras. 2010. 140f. Dissertação (Mestrado em Ciência da Informação) - Universidade Estadual Paulista, Marília, SP.

MILANI, S. O.; PINHO, F. A. Knowledge Representation and Orthophemism: a Reflection Aiming to a Concept. Knowledge Organization, v. 39, p. 384-393, 2012.

MURPHY, T. F. (Ed.). Reader's guide to lesbian and gay studies. Chicago: Fitzroy Dearborn Publishers, 2000.

NOVAK, J. D. Uma teoria da educação. São Paulo: Pioneira, 1980. 252p.

OLSON, H. A. Mapping beyond dewey's boundaries: constructing classificatory space for marginalized knowledge domains (Dewey Decimal Classification excludes some groups). Library Trends, Champaign, v. 47, n. 2, p. 233-254, 1998.

OLSON, H. A. The power to name: locating the limits or subject representation in libraries. Dordrecht: Kluwer Academic Publisher, 2002.

OLSON, H. A. Transgressive deconstructions: feminist/ postcolonial methodology for research in Knowledge Organization. In: FRÍAS, J. A.; TRAVIESO, C. (Org.). Tendencias de investigación en organización del conocimiento. Salamanca: Universidad de Salamanca, 2003. p. 731-740.

PINHO, F. A. Aspectos éticos em representação do conhecimento: em busca do diálogo entre Antonio García Gutiérrez, Michèle Hudon e Clare Beghtol. 2006. 123 f. Dissertação (Mestrado em Ciência da Informação) Universidade Estadual Paulista, Marília, SP.

PINHO, F. A.; GUIMARÃES, J. A. C. Reflexiones acerca de las teorías sobre ética en la representación del conocimiento. In: ENCUENTROS INTERNACIONALES SOBRE SISTEMAS DE INFORMACIÓN Y DOCUMENTACIÓN, 11., 2006, Zaragoza. Anales. Zaragoza: Universidad de Zaragoza, 2006.

PINHO, F. A. Aspectos éticos em representação do conhecimento em temáticas relativas à homossexualidade masculina: uma análise da precisão em linguagens de indexação brasileiras. 2010. 149 f. Tese (Doutorado em Ciência da Informação) - Universidade Estadual Paulista, Marília, SP.

PINHO, F. A. Metafiltro para controle terminológico de metáforas no domínio da homossexualidade masculina. Ciência da Informação, Brasília, v. 43, n. 1, p. 120-133, $2014 . \quad$ Disponível em: <http://revista.ibict.br/ciinf/article/view/1422/1600>. Acesso em: 27 set. 2017.

Inf. Inf., Londrina, v. 22, n. 2, p. 117 - 143, maio/ago., 2017. http:www.uel.br/revistas/informacao/ 
PINHO, F. A.; MILANI, S. O. Metáfora e ortofemismo na representação de assunto. In: DODEBEI, V.; GUIMARÃES, J. A. C.. (Org.). Complexidade e organização do conhecimento: desafios de nosso século. Marília: FUNDEPE, 2013. p. 246-251.

RANGANATHAN, S. R. Faceted analysis. In: CHAN, L. M. et al. (Ed). Theory

of subject analysis. Littleton, CO: Libraries Unlimited., 1985. p. 86-93.

\title{
Title
}

Research course for contextualization of metaphors related to gender and sexuality in documentary languages

\begin{abstract}
Introduction: The construction of a line of research is accomplished by a long path and many theoretical and methodological reflections. In this sense, it is important to reflect on the investigative path that materialized this line of research. This is because the studies that allow this recall are incipient. In addition, this type of reflection allows understanding the evolution of the research and the understanding of how the data were interpreted and analyzed. Objective: This paper aims to present a theoretical and methodological reflection on an investigative course on metaphors related to gender and sexuality in documentary languages. Methodology: The methodology was based on exploratory, documentary and bibliographical research, with emphasis on thematic documents on gender and sexuality issues in the organization and representation of information and knowledge. Results: The results showed the detail of the data collection and the way they were analyzed, being the main interpretations based on the collection of keywords in specialized magazines, the translation and categorization of these words, the application of the metafilter, the construction of conceptual maps and the first attempt to include metaphors in documentary languages. Conclusions: Therefore, this reflection on the research path to contextualization of metaphors promotes not only an overview, but also possible trends and challenges for future research on organization and representation of information and knowledge and the question of gender and sexuality.
\end{abstract}

Keywords: Organization of knowledge. Documentary languages. Gender. Sexuality.

\section{Título}

Percurso investigativo para la contextualización de metáforas relativas a género y sexualidad en lenguajes documentales

\section{Resumen}

Introducción: La construcción de una línea de investigación se realiza por un largo camino y muchas reflexiones teóricas y metodológicas. En ese sentido, es importante

Inf. Inf., Londrina, v. 22, n. 2, p. 117 - 143, maio/ago., 2017.

http:www.uel.br/revistas/informacao/ 
reflexionar sobre el recorrido investigativo que materializó esa línea de investigación. Esto es porque los estudios que permiten esta rememoración son incipientes. Además, este tipo de reflexión permite que se comprenda la evolución de la investigación y la comprensión de cómo los datos fueron interpretados y analizados. Objetivo: En este artículo, se objetivó presentar una reflexión teórica y metodológica acerca de un recorrido investigativo sobre metáforas relativas al género y sexualidad en lenguajes documentales. Metodología: La metodología se basó en la investigación exploratoria, documental y bibliográfica, se enfatizó los documentos con temáticas acerca de cuestiones de género y sexualidad en el ámbito de la organización y representación de la información y del conocimiento. Resultados: Los resultados mostraron el detalle de la recolección de los datos y la forma en que se analizaron, siendo las principales interpretaciones basadas en la recolección de palabras clave en revistas especializadas, la traducción y categorización de esas palabras, la aplicación del metafiltro, la construcción de mapas conceptuales y el primer intento de inclusión de metáforas en lenguajes documentales. Conclusiones: Por lo tanto, esta reflexión sobre el recorrido investigativo para contextualización de metáforas promueve no sólo una visión general, sino posibles tendencias y desafíos para futuras investigaciones en organización y representación de la información y del conocimiento y la cuestión de género y sexualidad.

Palabras clave: Organización del conocimiento. Lenguajes documentales. Género. Sexualidad.

Recebido: 10.03.2017

Aceito: 25.08.2017

Inf. Inf., Londrina, v. 22, n. 2, p. 117 - 143, maio/ago., 2017.

http:www.uel.br/revistas/informacao/ 